Results Mean age was 50.6 (21.3). 44\% male. 53\% used NIV at night. All were naïve to NIV during exercise. NIV increased cycle time by $146 \mathrm{~s}(105 \%)$. All stated they would be prepared to repeat this type of exercise (Abstract P269 table 1).

Conclusion NIV is well tolerated, feasible and significantly increases exercise capacity in patients hospitalised with an acute exacerbation of respiratory disease.

\section{P270 MOTOR NEURONE DISEASE (MND); A SURVEY OF DEATHS IN THE ERA OF NON-INVASIVE VENTILATION}

doi:10.1136/thoraxjnl-2011-201054c.270

S K Banerjee, M G Davies, I E Smith. Papworth Hospital NHS Foundation Trust, Papworth Everard, UK

Background The care of patients with MND has changed radically with greater uptake of non-invasive ventilation (NIV) and tube feeding (TF). Community colleagues in our region have expressed anxiety about how such supported patients might die and in particular whether the process of dying might be prolonged. We sought to investigate these concerns.

Methods A structured questionnaire was distributed to involved clinicians, community practitioners and MNDA care co-ordinators. They completed questionnaires for patients dying under their care, where necessary/appropriate with the input of family members. The data are compared with an historical, retrospective series $(\mathrm{n}=50)$ reported by the Wisdom Hospice $(\mathrm{WH}){ }^{1}$

Results From October 2010 to June 2011, 51 deaths were recorded (mean age 67 years, 29 men). Thirty deaths were in an acute hospital, 15 at home, six in a hospice or community hospital. 16 patients had advance care plans (ACP) of whom 10 died in their "preferred place". Assisted ventilation had been prescribed to 30 and tube feeding to 37 patients. NIV and TF were discontinued before death in 13 and five patients respectively. For 22 patients the process of dying was sudden or $<24 \mathrm{~h}$ in duration. NIV was not associated with a prolonged process of dying. The commonest certified cause of death was an unqualified "MND", with pneumonia reported in seven cases. No patient had a post mortem examination. The WH cohort had a similar proportion of men and the mean age at death was 66 years. None of the patients had assisted ventilation and only seven had tube feeding. The process of dying was $24 \mathrm{~h}$ or less for 24 patients. The commonest recorded cause of death was respiratory failure (22 individuals).

Conclusion These preliminary results show that there is no trend to prolonged deaths in patients with MND using NIV and TF. Several patients have elected to discontinue NIV. ACP's in our region remain patchy and require further attention. The quality of death certification is poor with little detail on the mechanism of death.

\section{REFERENCE}

1. Neudert C, Oliver D, Borasio GD, et al. The course of the terminal phase in patients with amyotrophic lateral sclerosis. J Neurol 2001:248:612-16.

\section{P271 IMPACT OF STRUCTURED REFERRAL AND FOLLOW-UP PATHWAYS ON ACCESS TO VENTILATORY SUPPORT FOR PEOPLE WITH MOTOR NEURONE DISEASE (MND)}

\section{doi:10.1136/thoraxjn-2011-201054c.271}

S K Banerjee, M G Davies, I E Smith. Papworth Hospital NHS Foundation Trust, Papworth Everard, UK

Introduction Attitudes to surveillance for and treatment of ventilatory failure among people with MND have changed over several years. In the UK this culminated in the publication in July 2010 of National Institute of Clinical Excellence (NICE) guidance designed to increase access to non-invasive ventilation (NIV). The services offered in our respiratory unit have evolved on the basis of published evidence in advance of formal guidelines. We examined the impact of compliance with practice parameter recommendations in NICE to our referral numbers and uptake of NIV in East Anglia.

Methods A retrospective review of number of referrals and new NIV starters from 1984 to 2010 in a regional respiratory support unit. Between 2001 and 2005 the MND Association helped to establish a care centre in Cambridge and closer working was established with the respiratory service. From 2006 the default position was to offer all patients newly diagnosed with MND a respiratory assessment and structured 3 monthly follow-up appointments in a fashion subsequently detailed in the NICE guidance.

Results The numbers of new referrals and people starting NIV are shown in Abstract P271 figure 1. Between 1984 and 2000 there was slow growth but the mean annual values were just seven referrals and four new NIV starters (57\%). With closer working between neurologists in the care centre and the respiratory unit between 2001 and 2005 mean referral numbers increased to 31 with 17 new NIV starters (55\%) per year. With default referral and 3 monthly reviews the number referred grew to 44 with around 31 NIV starters per year $(70 \%)$

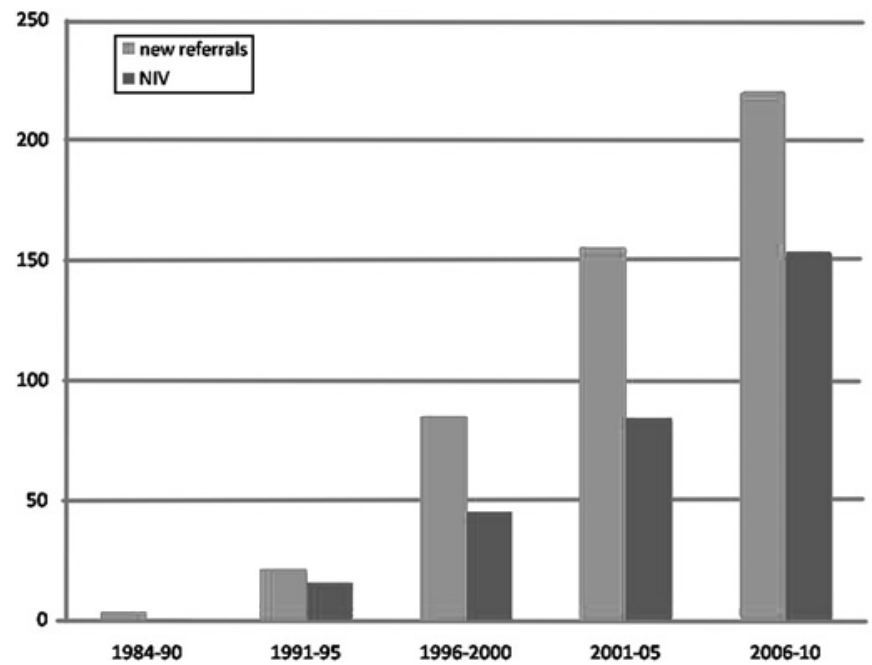

Abstract P271 Figure 1

Conclusion With an estimated population of 2.5 million in East Anglia, and an annual incidence of 2.8 per 100000 we estimate 70 new cases of MND per year. Around $60 \%$ of patients are therefore being referred and $70 \%$ of these are starting NIV. Implementing the NICE guidance could have a similar impact across the UK, a great improvement on the position in 2000 when only around $3 \%$ of patients were being offered NIV. ${ }^{1}$

\section{REFERENCE}

1. Bourke SC, Williams TL, Bullock RE, et al. Non-invasive ventilation in motor neurone disease: current UK practice. Amyotroph Lateral Scler Other Motor Neuron Disord 2002;3:145-9.

\section{P272 A 7 YEAR RETROSPECTIVE EVALUATION OF INITIATION OF LONG TERM NON-INVASIVE VENTILATORY SUPPORT FOR MOTOR NEURONE DISEASE}

doi:10.1136/thoraxjnl-2011-201054c.272

J Palmer, P Hughes. Plymouth Hospitals NHS Trust, Plymouth, UK

In 2010 NICE (1) published it's guideline for the use of non-invasive ventilation in the management of motor neurone disease (MND). We have offered long-term non-invasive ventilation (NIV) in this 